\title{
The Types of Argument Structure Used by Hillary Clinton in the CNN Democratic Presidential Debate
}

\author{
Nani Indrajani T., Anggie Angeline \\ English Department, Faculty of Letters, Petra Christian University \\ Siwalankerto 121-131, Surabaya 60236, East Java, Indonesia \\ e-mail: nitiono@peter.petra.ac.id; anggie.angeline@molindo.com
}

\begin{abstract}
This qualitative research was conducted to examine the types of argument structure by Hillary Clinton in part one of the CNN Democratic Presidential Debate since Hillary, who had a great deal of experiences in political parties, was supposed to be able to construct convincing arguments that had good argument structures. The theories used to analyze were Bierman and Assali's (1996), King's (n.d.) and Stanlick's (2003). The findings showed that there were five types of argument structure used: serial, linked, convergent, divergent, and hybrid argument structures. The linked argument structure was the argument structure used the most frequently in Hillary's utterances in the debate, while the divergent was the least one. Thus, it could be concluded that Hillary's speech in the Presidential Debate was quite interesting since she could combine all the five types of argument structure, though the frequency of using them was not the same and it seems that linked argument structure was the most effective strategy for her in arguing about the politic, economy, and social issues.
\end{abstract}

Key words: debate, argument, argument structure, premise, conclusion.

In persuasive communications, arguments are very important because a speaker has to convince the listeners and since "every argument in logic has a structure, and every argument can be described in terms of this structure", the speaker should be able to construct arguments that have good argument structures ("Introduction to Logic", n.d.) According to Bierman and Assali (1996), "an argument is a sequence of statements in which statements, called premises, are given as reasons or evidence for the truth of a statement, called the conclusion" (p. 33). Moore and Parker (1986) also stated that "an argument consists of a conclusion (the claim that is argued for) and premises (the claims that provide the readers or hearers with reasons for believing the conclusion)" (p. 182). An argument must be formed with its premises and conclusion, for example: 
[Premise] Every officer on the force has been certified, and [premise] nobody can be certified without scoring above 70 percent on the firing range. Therefore, [conclusion] every officer on the force must have scored above 70 percent on the firing range. (p. 182)

Sometimes some arguments have unstated premise and conclusion. In this case, inference indicators signal the occurrence of the premise and conclusion, for example: [Premise] "You can't check books out of the library without an ID card. So [conclusion] Bill won't be able to check any books out” (p. 182). The word 'so' is the inference indicator to signal the conclusion.

Arguments can be categorized as 'deductive' and 'inductive' arguments (Bierman \& Assali, 1996). An argument in which "the truth of its premises is intended to guarantee the truth of its conclusion" is called as deductive argument (p. 40); in this case, if the premises are true, the conclusion must be true. However, an argument in which "the truth of its premises is intended to make likely, but not guarantee, the truth of its conclusion' is called as inductive argument (p. 40).

They also stated that there are three types of argument structure: serial, linked, and convergent argument structures. In a serial type of argument structure, "each intermediate conclusion is a premise for the next step in the argument” (p. 84). In this type of argument structure, one premise leads to another in a chain until it leads to the conclusion. Before coming to a main conclusion of the whole argument, there may be a series of sub-conclusion that follows from the previous premises and then function as yet another premise for the next conclusion, either sub or main (King, n.d., p. 5).

In the second type of argument structure, linked argument structure, premises "stand together to support a conclusion ... and are connected by underlining and plus signs" (Bierman \& Assali, 1996, p. 86). "In a linked argument structure, each premise requires the help of the other(s) in order to provide support for the conclusion. The premises rely dependently on each other and the conclusion would not follow without the two (or more) pieces of information being considered one" (p. 3).

The third type is convergent or split support argument, that is, "an argument with two or more separate lines of reasoning leading to the same conclusion" (p. 86). "In a convergent argument, each premise supports the conclusion to some extent by itself, independently of the other(s). So even if a premise in such an argument is doubtful, it is possible that the other(s) still establish the conclusion” (p. 4). 
In line with Bierman and Assali's theory, there is also another type of argument structure based on Stanlick (2003). This type of argument structure is called "divergent argument structure". Divergent structure occurs when there is one premise or reason leads to more than one conclusion.

As an addition, "complex reasoning usually involves two or all four of these structural elements; serial, linked, convergent and divergent" (King, n.d., p. 6). Another type which is called 'hybrid structure' is the combination of the four types of argument structures. It can be a combination between serial and convergent argument structures, convergent and linked argument structures, and the combination between the four argument structures above.

Talking about argument, this term is usually used in the political field, such as in a debate. "Debate, in fact, is defined as competitive advocacy, oral or written, for and against a proposition, occurring with or without limitations of time, place, or form” (Klopf \& McCroskey, 1969, p. 10). In a debate, a debater can present a series of arguments in order to persuade the audience to accept his or her views on an issue. Besides that, he or she can also present a series of arguments to express his or her disagreements about something. This kind of communication becomes controversial as the various sides attack the other's ideas and defend their own. (p. 10).

In this research, the writers were interested in investigating argument in part one of the CNN Democratic Presidential Debate, specifically Hillary's Democratic Presidential Debate because this part of the debate was about social, economic, political, and other controversial issues that all Americans had to face. The debate focused on why certain programs should be done to help the Americans deal with the problems that have happened recently. Hillary was chosen as the subject of investigation because she was a strong candidate of the Democrat Party who had distinctive strategies in posing her arguments. As a result of debates, meetings and forums that she had participated as a senator, she has developed for herself an astute ability to present her arguments well and with solid supports. As a candidate of the presidential election, Hillary had to gain people's trust through all of her speeches and arguments in the campaigns. Thus, she would construct her arguments carefully and would not let her opponents easily attack her.

Based on the phenomenon above, the writers were interested in analyzing the types of argument structure and the one used the most frequently by Hillary Clinton in part one of the CNN Democratic Presidential Debate. 


\section{METHODS}

The approach of this research was qualitative. The source of data was taken from Hillary's utterances in part one of the Democratic Presidential Debate which was sponsored by $\mathrm{CNN}$ and the Congressional Black Caucus Institute on January 21, 2008 (CNN Democratic Presidential Debate, n.d.). Meanwhile, the data were only the utterances that contained arguments which were produced by Hillary in the presidential debate.

To identify which utterances were said to be arguments, first, it is necessary to see whether an utterance has a sequence of statements which function as premises or not. Second, it is important to see whether the utterance has statement which functions as conclusion or not. Thus, an utterance cannot be identified as argument if there is only one statement inside it and there is not any statement which functions as conclusion.

In analyzing the data, the writers had to find out the statements or claims which were produced by Hillary in each argument. Besides finding the claims, the writers also had to bracket and number each claim in the argument. Words and phrases that added nothing to the argument were left out of the brackets. In this case, all sentences which were not categorized as arguments were also left out of the brackets. If the same claim was stated more than once in a sentence, the claims got the same number an only one of them was put in the index of claims.

After finding the claims and doing the process of bracketing and numbering, the writers needed to make the index of the claims and also find out the premises and conclusion of an argument. To make it easier to find out the premises and the main conclusion of the argument, the inference indicators were underlined. For example: "1[It is not going to be easy]. 2[Withdrawing troops is dangerous]. That's why 3[I've been working to make sure that we knew all of the various steps we would have to take], because 4[it's not just bringing our troops and equipment home]."

Next, a diagram of the argument which was called as tree diagram was drawn in order to find out the type of the argument structure. In making the diagram, the method proposed by Bierman and Assali (1996) was used, that is, the use of numbers $(1,2,3)$ to signal the explicit claims, letters (A, $\mathrm{B}, \mathrm{C}$ ) to signal the implicit premises, a straight arrow to indicate deductive argument and could be read as 'therefore', the plus sign (+), which was always used in the linked type, to show that there was more than one premise standing together. 
After drawing the tree diagram, the argument was classified into the types of argument structure and the total of each type of argument structure was calculated manually in order to find out the percentages of each type of argument structure used by Hillary in the whole argument. From the percentages, the type of argument structure used the most frequently by Hillary in the debate could be seen.

\section{FINDINGS AND DISCUSSION}

From Figure 1, it could be seen that from the nineteen arguments found in her utterances in part one of the CNN Democratic Presidential Debate, Hillary used all the five types of argument structure: serial, linked, convergent, divergent, and hybrid argument structures, though the frequency of using them was different. From the findings, the linked argument structure turned out to be the argument structure used the most frequently in Hillary's utterances in the debate. The linked argument structure reached $36.84 \%$ of the total types of the argument structure. The second most common type of argument structure was the convergent argument structure with the percentage of $31.57 \%$. The serial argument structure was the third most common type after the convergent argument structure with the percentage of $15.78 \%$. Next was the hybrid argument structure with a portion of $10.52 \%$ of all types. The hybrid type had two different combinations: the combination of convergent and linked argument structures and the combination of serial and convergent argument structures. The least discovered type of argument structure was the divergent type which only reached $5.26 \%$ of all types.

In the beginning part of her debate, when she talked about her economic strategy, Hillary used four types of the argument structure: the divergent, linked, convergent, and serial argument structures consecutively. Though in this part she did not use the hybrid argument structure and it was the only part where divergent argument structure could be found, this variation of argument structures made the beginning of her speech interesting and not monotonous so that it stimulated people to listen to her. The link and convergent argument structures were spread in all parts of her debate; the serial argument structure could be found again in nearly the ending part and at the end of her debate; and the hybrid argument structure could only be found after the middle part of her debate. 


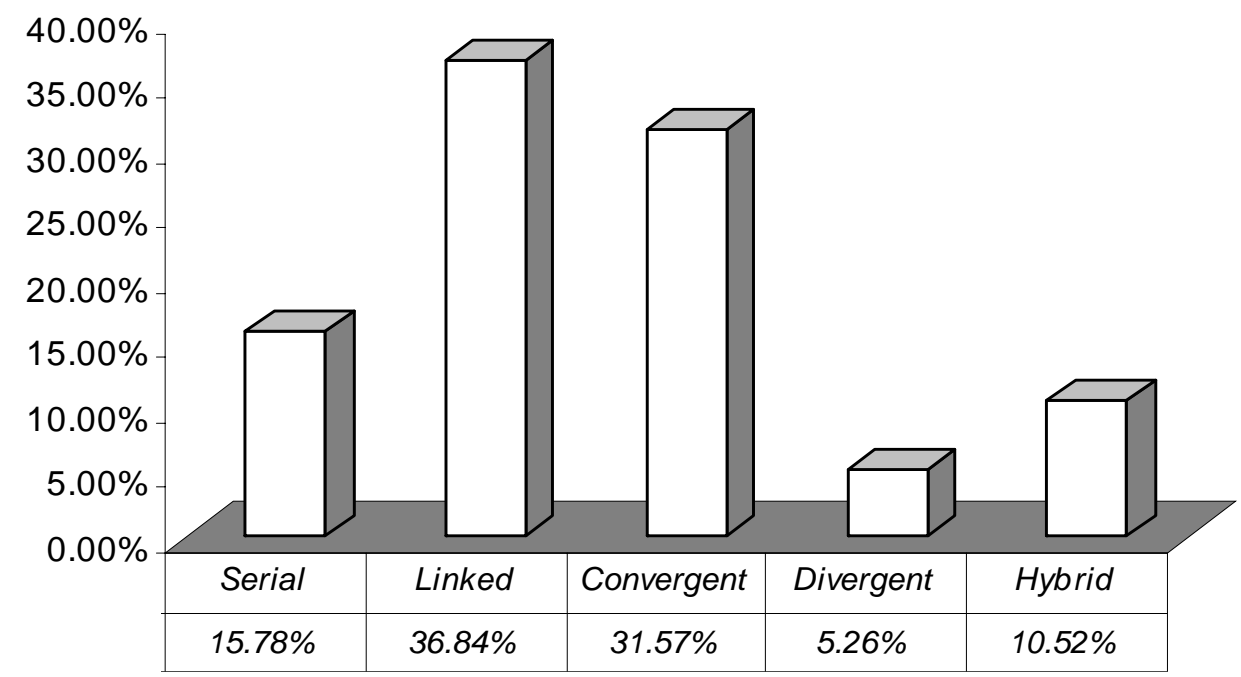

Figure 1. The Types of Argument Structure Used by Hillary Clinton in Part One of the CNN Democratic Presidential Debate

\section{Linked Argument Structure}

In this type of argument structure, "each premise requires the help of the other(s) in order to provide support for the conclusion. The premises rely dependently on each other and the conclusion would not follow without the two (or more) pieces of information being considered one" (King, n.d., p. 3). It was found that in Hillary's Democratic Presidential Debate, linked argument structure reached $36.84 \%$ from the total of the argument structure. This linked argument structure can be seen in the following example:

Well, I want to just clarify a couple of points. 1[My original plan was $\$ 70$ billion in spending with a $\$ 40$ billion contingency that was part of the original plan], in order to 2[have that money available for tax rebates]. I hope that we could do it through spending, and here's why: 3[I don't want to necessarily open up the tax code while we've got Republicans in the Senate who are going to try to come back and open up making Bush's tax cuts permanent].

The index of claims:

1. My original plan was $\$ 70$ billion in spending with a $\$ 40$ billion contingency that was part of the original plan.

2. Having money for tax rebate. 
3. I don't want to necessarily open up the tax code while we've got Republicans in the Senate who are going to try to come back and open up making Bush's tax cuts permanent.

From the index of claims above, claims numbers 1 and 3 are categorized as premises since those statements are given as reasons for the truth of the conclusion, as stated in the claim number 2 . Since the claims numbers 1 and 3 lead to the conclusion (claim number 2), the argument diagram is seen as in Diagram 1.

\section{Diagram 1:}

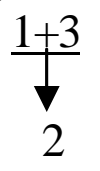

The type of argument structure from the argument above is linked structure because the premises (claims numbers 1 and 3) depend on each other to support the conclusion (claim number 2). Another example is:

As a further point, 1[I do believe that the green-collar job piece of this is important]. That's why 2[I have $\$ 5$ billion to do it]. There are programs already. Oakland, California, Mayor Dellums is working to have a green-collar job program. 3[We could put hundreds and hundreds of young people to work right now, putting solar panels in, insulating homes].

The index of claims:

1. I do believe that the green-collar job program is important.

2. I have $\$ 5$ billion to do the green-collar job program.

3. We could put hundreds and hundreds of young people to work right now, putting solar panels in, insulating homes.

From the index of claims above, claims numbers 1 and 3 are categorized as premises since those statements are given as reasons for the truth of the conclusion, as stated in claim number 2. Claim number 2 is categorized as conclusion since there is an inference indicator "that's why" that serves to signal the conclusion of the argument above. Thus, claims numbers 1 and 3 lead to the conclusion (claim number 2) and the argument diagram is shown in Diagram 2. 
Diagram 2:

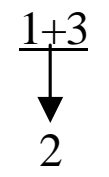

The type of argument structure from the argument above is linked structure. It is linked because the premises (claims numbers 1 and 3) depend on each other to support the conclusion (claim number 2). The third example is:

1[I would have a moratorium on home foreclosures for 90 days to try to help families work it out so that they don't lose their homes]. 2[We're in danger of seeing millions of Americans become basically, you know, homeless and losing the American dream].

The index of claims:

1. I would have a moratorium on home foreclosures for 90 days to try to help families work it out so that they don't lose their homes.

2. We are in danger of seeing millions of Americans become homeless and losing the American dream.

From the index of claims above, claim number 2 is the premise since it is a statement that is given as reason for the truth of the conclusion, as stated in the claim number 1 . Thus, claim number 2 leads to the conclusion (claim number 1) and has argument diagram as seen in Diagram 3:

Diagram 3:

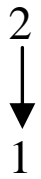

Though the argument in Diagram 5 is categorized as deductive argument (the truth of its premise is intended to guarantee the truth of its conclusion), the argument is still invalid since one premise or reason only cannot guarantee that the conclusion is true. Besides, the claim number 2 cannot directly lead to the claim number 1 since it is not logical to draw a conclusion that "I would have a moratorium on home foreclosures for 90 
days to try to help families work it out so that they don't lose their home” from the premise "We are in danger of seeing millions of Americans become homeless and losing the American dream" without knowing what kind of American dream that is being discussed in this context. Thus, an implicit premise should be added in the index of claims with the label A:

1. I would have a moratorium on home foreclosures for 90 days to try to help families work it out so that they don't lose their homes.

2. We are in danger of seeing millions of Americans become homeless and losing the American dream.

A. The home foreclosures will destroy the dreams of Americans for home ownership.

The argument diagram could be as seen in Diagram 4.

Diagram 4:

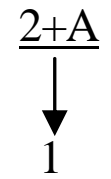

It belongs to linked argument structure because the premises (claim number 2 and the implicit premise A) depend on each other to support the conclusion (claim number 1).

\section{Convergent Argument Structure}

"A convergent or split support argument is an argument with two or more separate lines of reasoning leading to the same conclusion" (Bierman \& Assali, 1996, p. 86). Convergent argument structure in the findings was the second most common type of argument structure with the percentage of $31.57 \%$. For examples:

1[I want to have an interest rate freeze for five years], because 2[these adjustable-rate mortgages, if they keep going up, the problem will just get compounded]. And 3[we need more transparency in the market].

The index of claims:

1. I want to have an interest rate freeze for five years.

2. If these adjustable rate mortgages keep going up, the problem will get compounded.

3. We need more transparency in the market. 
From the index of claims above, claims numbers 2 and 3 are categorized as premises since those statements are given as reasons for the truth of the conclusion, as stated in the claim number 1 . The inference indicator "because" also indicates that the claim number 2 is categorized as premise. Since the claims numbers 2 and 3 lead to the conclusion (claim number 1 ), the argument diagram is seen as Diagram 5.

Diagram 5:

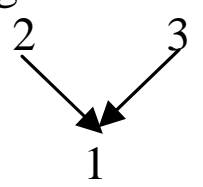

The type of argument structure from the argument above is convergent structure because there are two separate lines of reasoning leading to the same conclusion.

Then, 1[I think we need to give people about $\$ 650$, if they qualify -which will be millions of people -- to help pay their energy bills this winter]. You know, 2[there are so many people on fixed incomes] and 3 [working people who are not going to be able to afford the spike in energy costs].

The index of claims:

1. I think we need to give people about $\$ 650$ to help to pay their energy bills this winter.

2. There are so many people on fixed incomes who are not going to be able to afford the spike in energy costs.

3. There are so many working people who are not going to be able to afford the spike in the energy costs.

From the index of claims above, claims numbers 2 and 3 are categorized as premises since those statements are given as reasons for the truth of the conclusion, as stated in the claim number 1 . Since the claims numbers 2 and 3 lead to the conclusion (claim number 1), the argument diagram could be seen as in Diagram 6 .

Diagram 6:

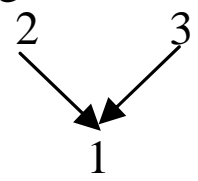


The type of argument structure from the argument above is convergent structure because there are two separate lines of reasoning leading to the same conclusion. Another example can be seen in the following utterances:

1[It is not going to be easy]. 2[Withdrawing troops is dangerous]. That's why 3[I've been working to make sure that we knew all of the various steps we would have to take], because 4[it's not just bringing our troops and equipment home]. 5[We have more than 100,000 civilians there, working for the embassy, working for businesses, working for charities].

The index of claims:

1. Withdrawing troops is not going to be easy.

2. Withdrawing troops is dangerous.

3. I've been working to make sure that we knew all of the various steps we would have to take in bringing our troops home.

4. It (withdrawing troops) is not just bringing our troops and equipment home.

5. We have more than 100,000 civilians there, who work for the embassy, businesses, and charities.

From the index of claims above, claims numbers 1, 2, 4, and 5 are categorized as premises since those statements are given as reasons for the truth of the conclusion, as stated in claim number 3 . The inference indicator "because" indicates that both claims numbers 4 and 5 are the premises of the previous statement (claim number 3). The inference indicator "that's why" also indicates that the claim number 3 is the conclusion of the argument. Since the claims numbers 1, 2, 4, and 5 lead to the conclusion (claim number 3). The type of argument structure is convergent structure because there are more than two separate lines of reasoning leading to the same conclusion. The argument diagram would be as in Diagram 7.

Diagram 7:

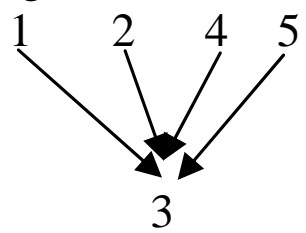




\section{Serial Argument Structure}

In this type of argument structure, "each intermediate conclusion is a premise for the next step in the argument” (Bierman \& Assali, 1996, p. 84). Serial argument structure got the percentage of $15.78 \%$. For example:

Well, first of all, 1[my health care program will cover everyone]. 2[I don't leave anybody out]. 3[It is a universal system].

The index of claims:

1. My health care program will cover everyone.

2. I don't leave anybody out from my health care program.

3. My health care program is a universal system.

From the index of claims above, claims numbers 1 and 2 are categorized as premises since those statements are given as reasons for the truth of the conclusion, as stated in the claim number 3. Since the claims numbers 1 and 2 lead to the conclusion (claim number 3), the argument diagram could be seen as in Diagram 8 in which each premise leads one to another in a chain until it leads to the main conclusion.

Diagram 8:

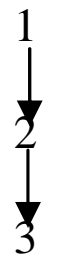

Another example of the serial argument structure found in Hillary's Presidential

Debate can be seen in the following example:

And then 1[we will have money for rebates], but let's make them the right rebates. Everything we know about 2[President Bush's plans would leave 50 million to 70 million Americans out], because 3[a lot of our seniors on fixed incomes don't pay income taxes]. But 4[that doesn't mean they're immune from the energy costs and the health care costs and everything else that's going up around them]. 
The index of claims:

1. We will have money for rebates.

2. President Bush's plans would leave 50 million to 70 million Americans out of the economy stimulus package.

3. A lot of our seniors on fixed incomes don't pay income taxes.

4. A lot of our seniors on fixed incomes have to pay the energy costs, health care costs, and everything else that's going up around them.

From the index of claims above, claim number 3 is categorized as premise since there is an inference indicator "because" that serve to signal the premise of the argument. Besides that, claims numbers 2 and 4 are also categorized as premises since those statements are given as reasons for the truth of the conclusion, as stated in the claim number 1 . As for the claims numbers 2 and 3, they serve both as sub-conclusions and also premises. Claim number 3 serves as sub-conclusion for the claim number 4 and serves as premise to support the claim number 2. Then, claim number 2 serves as sub-conclusion for the claim number 3 and serves as premise to support the conclusion (claim number 1). Since the claims numbers 2, 3, and 4 lead to the conclusion (claim number 1), the argument diagram is seen as in Diagram 9.

Diagram 9:

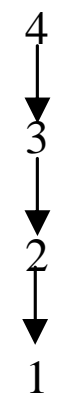

\section{Hybrid Argument Structure}

Hybrid structure is the combination of the four types of argument structure. It can be a combination of serial and convergent argument structures, convergent and linked argument structures, and the combination of the four argument structures above. In Hillary's Presidential Debate, hybrid argument structure took the percentage of $10.52 \%$ of all types and had two different combinations: the combination of convergent and linked 
argument structures and the combination of serial and convergent argument structures. For example:

Well, the fact is, 1 [the mortgage crisis is not only destroying the dreams of Americans for home ownership, 2[it is having a ripple effect across the world]. So 3[my moratorium for 90 days is a work-out]. 4[It's not a bailout]. 5[I want people to be able to see whether they can stay in their homes paying a rate that is affordable for them].

The index of claims:

1. The mortgage crisis destroys the dreams of Americans for home ownership.

2. The mortgage crisis has a ripple effect across the world.

3. My moratorium for 90 days is a work out.

4. My moratorium for 90 days is not a bailout.

5. I want people to be able to see whether they can stay in their homes paying a rate that is affordable for them.

From the index of claims above, claims numbers 1, 2, 3, and 4 are categorized as premises since those statements are given as reasons for the truth of the conclusion, as stated in claim number 5. Claims numbers 3 and 4 serve both as sub-conclusions and also premises. They serve as subconclusions for the claims numbers 1 and 2, and then they serve as premises to support the conclusion (claim number 5). Since the claims numbers 1, 2, 3, and 4 lead to the conclusion (claim number 5); Diagram 10 shows the argument diagram.

Diagram 10:

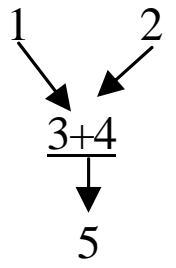

The type of argument structure from the argument above is hybrid structure (convergent $1 \rightarrow \underline{\underline{3}+4}$ and $2 \rightarrow \underline{3+4}$; linked $\underline{3+4} \rightarrow$ 5). It is convergent because there are two separate lines of reasoning leading to the same sub-conclusion. It is linked because each premise (claims numbers 3 and 4) depends on each other to support the conclusion (claim number 5). 
1[I believe what you're seeing happen is twofold]. 2[Of course the surge, the so-called surge, was able to pacify certain parts of Iraq]. 3[If we put enough of our men and women and equipment in we're going to be able to have some tactical military success]. But 4[the whole purpose of the surge was to force the Iraqi government to move quickly towards the kind of resolution that only it can bring about].

The index of claims:

1. I believe what you are seeing happen is twofold.

2. The surge was able to pacify certain parts in Iraq.

3. If we put enough our men and women and equipment in, we're going to be able to have some tactical military success.

4. The whole purpose of the surge was to force the Iraqi government to move quickly towards the kind of resolution that only it can bring about.

From the index of claims above, claims numbers 2, 3, and 4 are categorized as premises since those statements are given as reasons for the truth of the conclusion, as stated in claim number 1. Claim number 2 serves both as sub-conclusion and also premise. Claim number 2 serves as subconclusion for claim number 3 and as premise to support the conclusion (claim number 1). Since the claims numbers 2, 3 and 4 lead to the conclusion (claim number 1); Diagram 11 refers to the argument diagram.

\section{Diagram 11:}

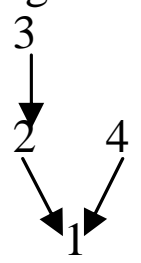

The type of argument structure from the argument above is hybrid structure (serial $3 \rightarrow 2$; convergent $2 \rightarrow 1$ and $4 \rightarrow 1$ ). It is serial because the claim number 3 leads directly to the sub-conclusion (claim number 2 ) in a chain. It is convergent because there are two separate lines of reasoning (claims numbers 2 and 4 ) leading to the same conclusion (claim number 1 ).

\section{Divergent Argument Structure}

"A divergent structure occurs when there is one premise or reason leads to more than one conclusion" (Stanlick, 2003). In Hillary's 
Presidential Debate, divergent type of argument structure was the least type used with the percentage of $5.26 \%$ of all types; some of them can be seen in the following examples.

1[We have to stimulate the economy]. 2[I began calling for some kind of economic action plan back at the beginning of December]. 3[I have a package of $\$ 110$ billion; $\$ 70$ billion of that would go towards dealing with the mortgage crisis], which, unfortunately, I don't think that President Bush has really taken seriously enough.

The index of claims:

1. We have to stimulate the economy.

2. I began calling for some kind of economic action plan back at the beginning of December.

3. I have a package of $\$ 110$ billion; $\$ 70$ billion of that would go towards dealing with the mortgage crisis.

From the index of claims above, claim number 1 is categorized as a premise since it is a statement that is given as reason for the truth of the conclusions, as stated in the claims numbers 2 and 3 . Since claim number 1 leads to the conclusions (claims numbers 2 and 3), the argument diagram would be as Diagram 12:

\section{Diagram 12:}

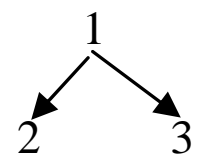

The type of argument structure from the argument above is divergent structure since the claim number 1 supports the claims numbers 2 and 3 as the conclusions (main conclusion 1: claim number 2, and main conclusion 2: claim number 3$)$.

\section{CONCLUSION}

Based on the findings above, it can be concluded that Hillary's speech in the Presidential Debate was quite interesting since she could combine all the five types of argument structure, though the frequency of using them 
was not the same. The variation of the argument structures Hillary used showed that she could construct convincing arguments with good argument structures and it seems that linked argument structure was the most effective strategy for her in arguing about the politic, economy, and social issues.

\section{REFERENCES}

Bierman, A. K., \& Assali, R. N. (1996) The critical thinking handbook. New Jersey: Prentice Hall.

CNN Democratic Presidential Debate. (n.d.). Retrieved April 24, 2008, from http://edition. cnn.com/2008/POLITICS/01/21/debate.transcript/index.html

Introduction to logic. (n.d.). Retrieved June 23, 2008, from http://philosophy. lander.edu/logic/structure.html

King, J. L. (n.d.) Argument structure. Retrieved June 6, 2008, from http://www. uncg.edu/phi/phi115/linked.htm

Klopf, D. W., \& McCroskey, J. C. (1969) The element of debate: The practical aspects of debating and the theories of argumentation. New York: Arco Publishing Company.

Moore, B. N., \& Parker, R. (1986). Critical thinking: Evaluating claims and arguments in everyday life. California: Mayfield Publishing Company.

Stanlick, N. A. (2003). Types of structures diagrams. Retrieved May 14, 2008, from http://pegasus.cc.ucf.edu/ stanlick/structurediagrams.html. 